\title{
A massive dentigerous cyst of the mandible in a young patient: a case report
}

\author{
Gururaj Arakeri', Kirthi Kumar Rai ${ }^{2}$, Hosadurga Rudraswami Shivakumar², \\ Shahanavaj I. Khaji ${ }^{3}$ \\ ${ }^{1}$ Department of Oral and Maxillofacial Surgery, Navodaya Dental College and Hospital, Raichur 584101, Karnataka, India. \\ ${ }^{2}$ Department of Oral Maxillofacial Surgery, Bapuji Dental College and Hospital, Davangere 577004, Karnataka, India. \\ ${ }^{3}$ Department of Oral and Maxillofacial Surgery, Tatyasaheb Kore Dental College and Research Centre, Kolhapur 416137, Maharashtra, \\ India.
}

Address for correspondence: Dr. Gururaj Arakeri, Department of Oral and Maxillofacial Surgery, Navodaya Dental College and Hospital, Raichur 584101, Karnataka, India. E-mail: gururaj.arakeri@gmail.com

\begin{abstract}
Cysts of the jaw present as swellings of jaws and midface. Of the different varieties, the dentigerous cyst is the most common type of noninflammatory odontogenic cyst and the frequent cause of a lytic lesion associated with an impacted tooth. The cyst develops from epithelial remnants of the tooth forming organ. The obstruction of venous flow due to compression of tooth follicle by developing tooth causes fluid accumulation between the follicular epithelium and the crown of the developing or unerupted tooth resulting in a cyst. Most small dentigerous cysts manifest in early age, usually as an incidental discovery in radiographic examinations. However, they can grow extremely large, asymptomatically, and remain undetected until they enlarge enough, causing bony expansion and asymptomatic facial swelling. We present a challenging case of massive dentigerous cyst in a 13-year-old female child involving half of the mandible, which was successfully treated with conservative therapy. This case report illustrates the effectiveness of simplified surgical treatment for a large dentigerous cyst in the mixed dentition period.
\end{abstract}

Key words:

Conservative therapy, cyst, massive dentigerous cyst

\section{INTRODUCTION}

In general, cysts of the jaw commonly present as swellings of the jaws and the midface. A sine qua non for the development of a dentigerous cyst is usually an unerupted tooth. The frequency of dentigerous cyst formation has been calculated as 1.44 in every 100 unerupted teeth. ${ }^{[1-3]}$

Dentigerous cysts occur over a wide age range with a peak frequency in the second to fourth decades and are the second most common odontogenic cysts after radicular

\begin{tabular}{|l|l|}
\multicolumn{2}{|c|}{ Access this article online } \\
\hline Quick Response Code: & Website: \\
\hline & www.parjournal.net \\
\hline & \\
\hline
\end{tabular}

cysts, accounting for approximately $24 \%$ of all true cysts in the jaws. ${ }^{[4-6]}$

Clinically, it is often asymptomatic; it is discovered as an incidental radiographic finding or when acute inflammation, infection or swelling develops ${ }^{[7-9]}$ where it appears as a well circumscribed, unilocular, usually symmetric radiolucency around the crown of an impacted tooth. As normal follicular space is $3-4 \mathrm{~mm}$, a dentigerous cyst can be suspected when the space

This is an open access article distributed under the terms of the Creative Commons Attribution-NonCommercial-ShareAlike 3.0 License, which allows others to remix, tweak, and build upon the work non-commercially, as long as the author is credited and the new creations are licensed under the identical terms.

For reprints contact: reprints@medknow.com

How to cite this article: Arakeri G, Rai KK, Shivakumar HR, Khaji SI. A massive dentigerous cyst of the mandible in a young patient: a case report. Plast Aesthet Res 2015;2:294-8.

Received: 22-11-2014; Accepted: 14-07-2015 
is more than $5 \mathrm{~mm}^{.1]}$ These cysts may also convert into ameloblastomas, mucoepidermoid carcinoma and squamous cell carcinoma. ${ }^{[10]}$

The growth rate may be quite rapid, with lesions growing up to $5 \mathrm{~cm}$ in diameter in 3-4 years. It can, however, become extremely large and is sometimes associated with cortical expansion and erosion. ${ }^{[3]}$ The expansion of these cysts is usually related to an increase in the osmolality resulting from passage of inflammatory cells and desquamated epithelial cells into the cystic lumen. ${ }^{[1]}$

We report a challenging case of massive dentigerous cyst involving the whole half of the mandible, which was successfully treated with conservative therapy. This report also illustrates a simplified surgical treatment for a large dentigerous cyst in the mixed dentition period.

\section{CASE REPORT}

A 13-year-old female child reported to the Department of Oral, Maxillofacial Surgery of Bapuji Dental College and Hospital, Davangere with a chief complaint of swelling over the left lower third of the face. The swelling was gradual and progressive as noted by the patient till the time of presentation [Figure 1]. There was no history of trauma. No episode of pain or discharge from the site was reported by the patient.

Patient was subjected to routine general systemic examination. She had no relevant past and present medical history. There was no history of cachexia or weight loss. Patient reported no contributory significant dental history. Local examination revealed an extraoral solitary swelling, which was oval in shape measuring about $5 \mathrm{~cm} \times 4.5 \mathrm{~cm}$. Swelling extended superiorly from the zygomatic arch region to $1 \mathrm{~cm}$ below the inferior border of the mandible inferiorly. Anteroposteriorly, it was extended about $3 \mathrm{~cm}$ from the tragus of the ear to the oral commissure. On palpation, the swelling was bony hard in consistency with a smooth surface. It was nontender with no pulsations; no egg-shell crackling was evident. Overlying skin was pinchable with no rise in local temperature and no secondary changes were evident. The patient had normal functioning cranial nerves $\mathrm{V}$ and VII. Lymph node examination ruled out the presence of any pathology with the nodes.

The patient had a maximal interincisal opening of $35 \mathrm{~mm}$. Teeth present were the second molar to second molar in the maxilla, and she had clinically missing both of the third molars. In the mandible, both the third molars as well as the second molar on the left side were absent. Lingual and buccal cortical expansion on the left side was evident.

Routine hematological investigations revealed normal values. The swelling was aspirated using a large bore needle and the straw-colored fluid revealed a high protein content of $5.1 \mathrm{~g} / 100 \mathrm{~mL}$.

Orthopantomogram [Figure 2] showed an expansile radiolucent lesion involving the left body, the ramus, condyle and coronoid processes measuring approximately
$3.0 \mathrm{~cm} \times 4.5 \mathrm{~cm}$ in size. The erupting left lower third molar was displaced and lying in close proximity to that of the sigmoid notch and the crown of the tooth was involved in the lesion. Second molar on the same side was also impacted wherein the lesion had encompassed the entire tooth. Gross thinning of both the cortices was noted in relation to the lesion and no definitive resorption of the root of any tooth was seen. Lesion was extending anteriorly to the root of left canine. Coronal and axial computed tomography (CT) scans [Figure 3] revealed almost symmetrical expansion of the medial and lateral cortices of the left condyle and also that of the ramus. No temporal bone involvement was seen.

Considering the factors such as age, site, as well as the high regenerative capacity of the musculo-periosteal

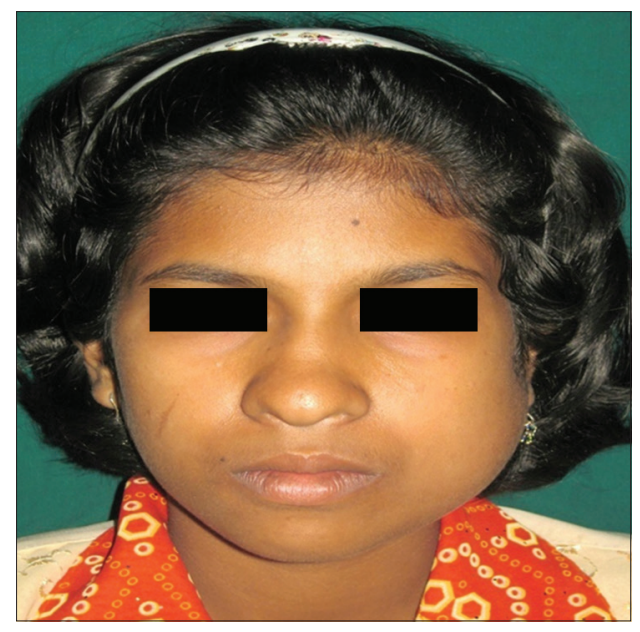

Figure 1: Preoperative profile

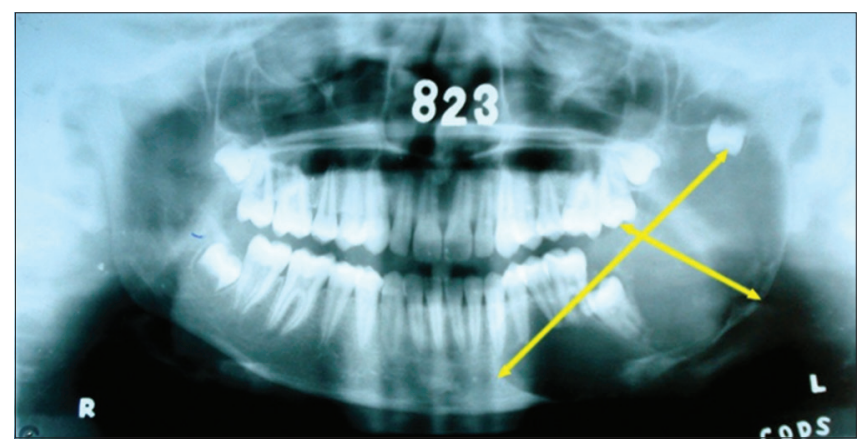

Figure 2: Preoperative orthopantomogram

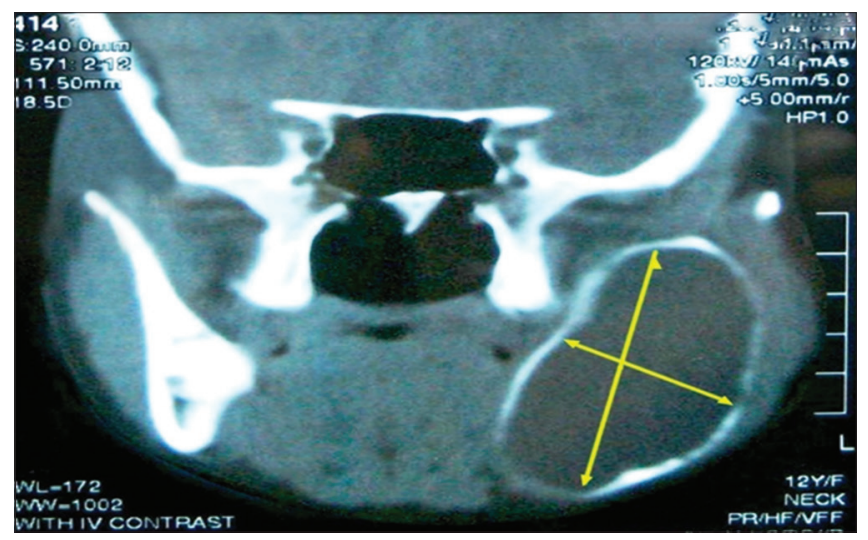

Figure 3: Preoperative CT scan 
capsule of the growing child, it was planned to treat the lesion with simple enucleation procedure.

Under general anesthesia, an intraoral incision was placed along the anterior border of the ramus and the coronoid process and lateral surface of the mandible were denuded [Figure 4]. The lesion was enucleated in total [Figures 5 and 6] along with the third molar. Extraction of the impacted second molar was carried out, and Carnoy's solution was applied along the entire bed of the lesion. Inferior alveolar nerve was preserved by applying Vaseline jelly [Figure 5]. Wire eyelets were placed on both sides and watertight wound closure was achieved using layered suturing. Intermaxillary fixation (IMF) was done on the first postoperative day (for 8 weeks) to maintain intercondylar distance. Her postoperative course was uneventful.

Histopathologic examination revealed the presence of a cystic lining and connective tissue capsule. The epithelial lining consisted of nonkeratinized 2-4 layers of flattened epithelial cells. The epithelial and connective tissue interface was flattened. The fibrous connective tissue wall was composed of dense collagen fibers and revealed islands of odontogenic epithelial rests, chronic inflammatory cells, chiefly plasma cells, and lymphocytes. All the features suggested a dentigerous cyst.

Patient was discharged on the 10th postoperative day with IMF and advised regular follow-up ( 2 weeks interval). On

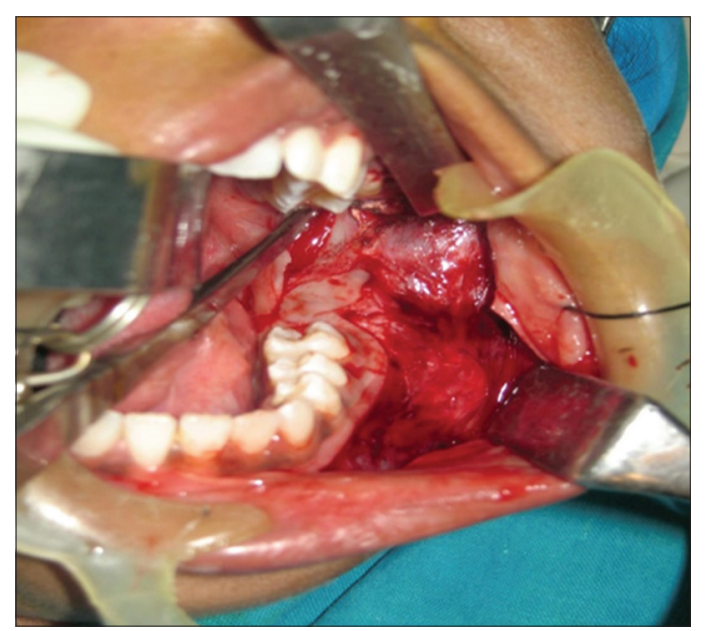

Figure 4: Intra oral exposure of cystic lesion

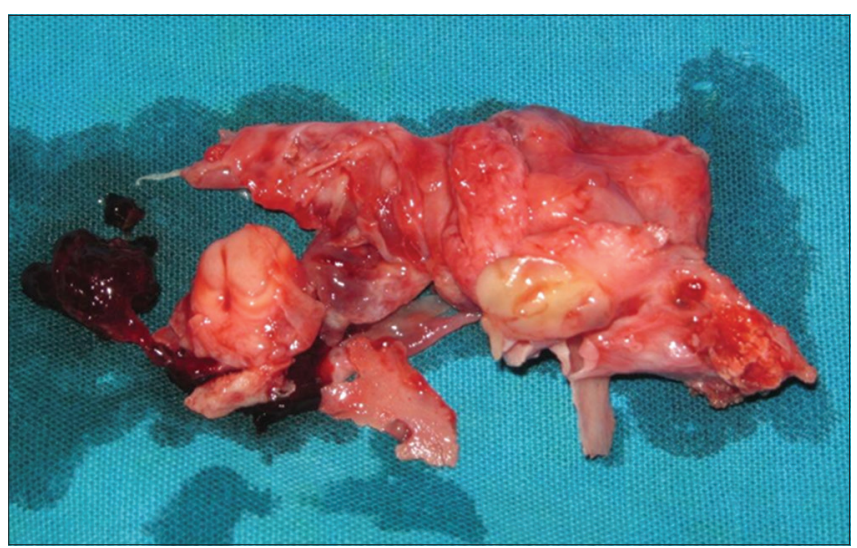

Figure 6: Enucleated specimen 8th week, IMF was released. As per our protocol, CT scans (both axial and coronal view) and radiographs were taken at regular intervals and evaluated. Radiographic follow-up revealed sufficient bone filling with increased bone density from the margin to the center of the defect when compared with the preoperative scans and radiographs [Figures 7-10].

\section{DISCUSSION}

Therapy for a cyst is determined by its etiology and localization, which, on the one hand, means that the causal tooth must be treated or removed and on the other that the cystic lining, which secretes the cystic content, must be excised. ${ }^{[12]}$ This statement fits well with the treatment characteristics of a dentigerous cyst.

Among various surgical treatment modalities to treat a dentigerous cyst, enucleation of the cyst is the most widely accepted procedure. Marsupialization is another treatment modality, which is usually employed for large dentigerous cysts due to its significant size, possibility of destruction of the surrounding tissue and concern for the potential of a pathologic fracture. ${ }^{[13]}$

Dentigerous cyst is more common in the third and fourth decades $^{[14]}$ and most of the surgical modality can be justified

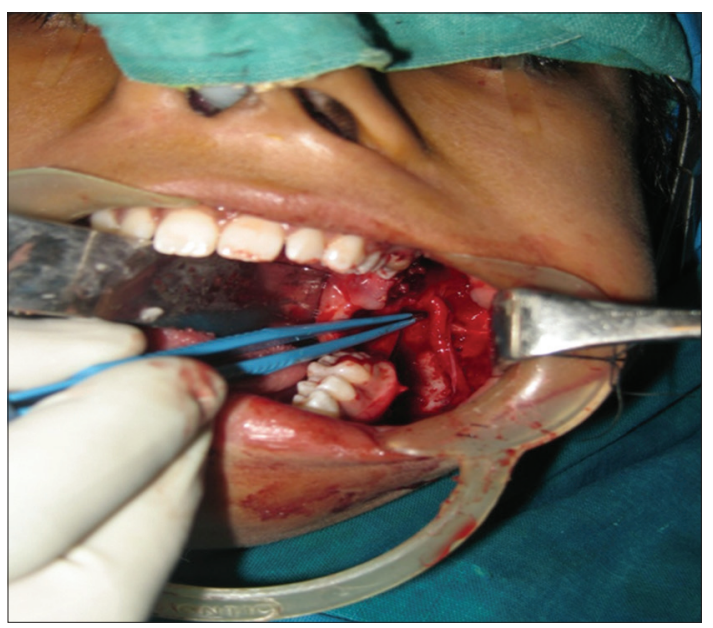

Figure 5: After enucleation inferior alveolar neurovascular bundle preserved

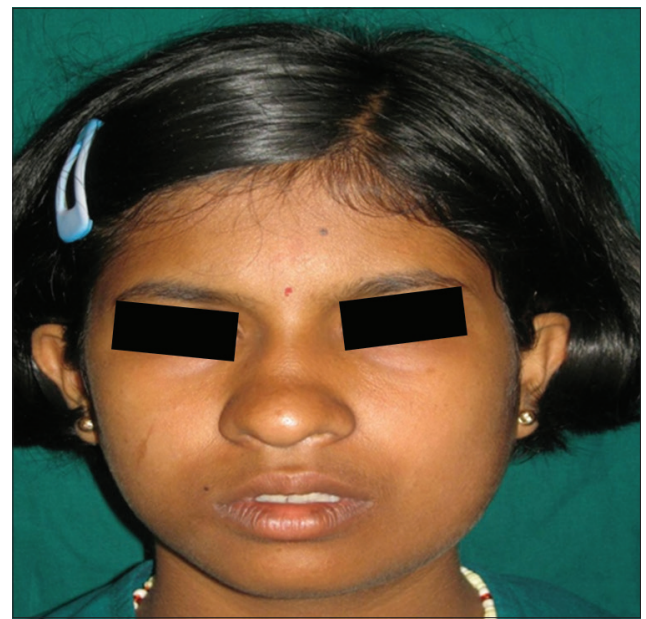

Figure 7: Three months post operative profile 


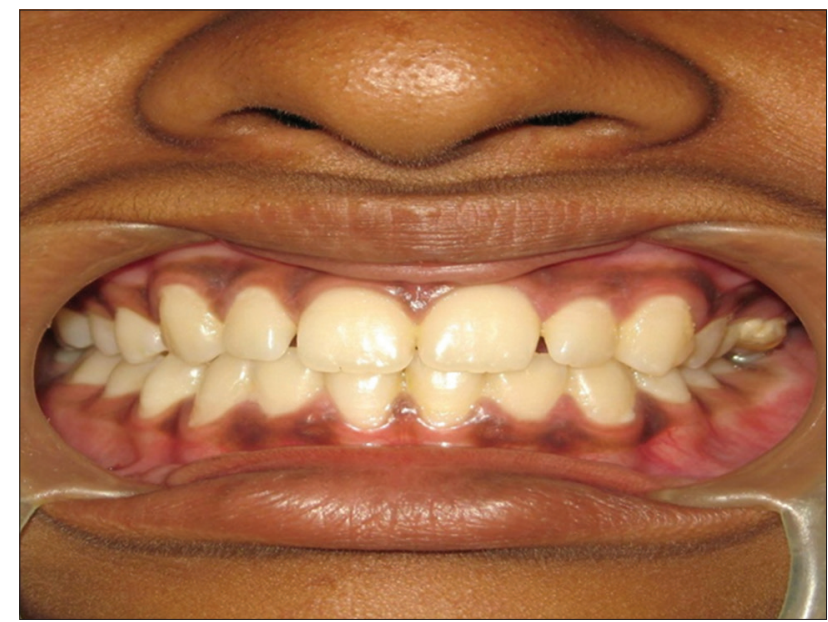

Figure 8: Three months post operative occlusal view (intact)

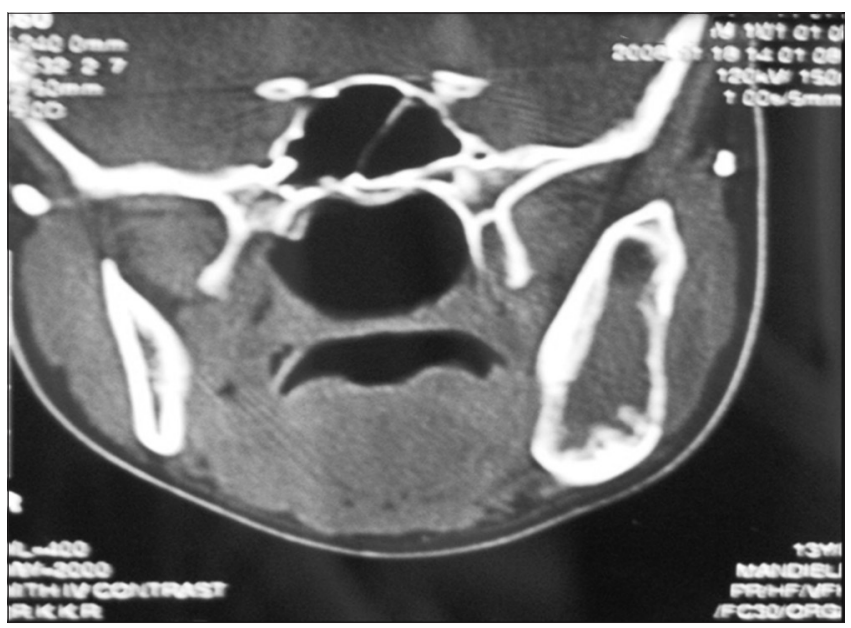

Figure 9: Three months CT scan showing bone filling in the defect

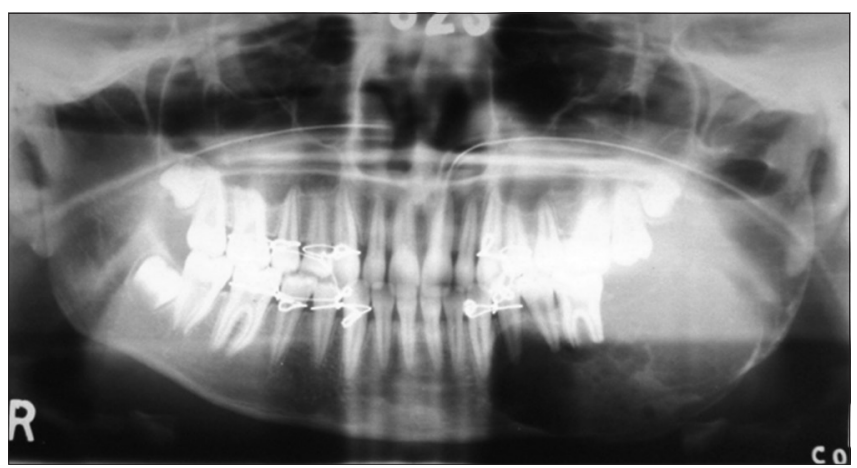

Figure 10: Three months post operative orthopantomogram showing successful bone regeneration

in those instances where jaws have completed the growth. But, choosing a treatment modality becomes critical when young growing jaws suffer a massive lesion. In the present case, the patient was only 13 years old at the time of presentation. Any radical approach may result in sever mutilation of the jaw along with the loss of its function.

In such situations proper decision making in selecting the appropriate treatment modality plays a crucial role in the prognosis of the overall therapy. For the present case, we had considered all possible modalities by taking into account the factors such as age, gender, location, size as well as the patient's socioeconomic status.
Although the well-considered modality, marsupialization satisfies certain therapeutic requirements in such large lesions, it has significant drawbacks such as slow healing and cicatrization. ${ }^{[12]}$ Moreover, this procedure is hard to rely on when treating a dentigerous cyst because it is difficult to maintain patency in a bony lesion. Also, a lateral window could drive the developing permanent dentition toward ectopic eruption, resulting in malocclusion and creating a potential need for further interceptive orthodontics. ${ }^{[7-9]}$

However, the treatment, prognosis and cure rates in such large dentigerous cysts are all dependent upon the various factors such as growth characteristics, anatomic site, clinical extent size, age, gender, etc.

Various studies have shown predictable spontaneous bone regeneration in young patients after enucleation of such large cysts. Many authors believe that bone grafting in young patients should be considered carefully and in most of the instances it is unnecessary. ${ }^{[1]}$

In view of the aforementioned, we preferred cystectomy rather a radical procedure, which may otherwise usually recommended in such large cysts. In our opinion, a radical treatment in a growing child might result in severe mutilation. Therefore, we would opine that it is always advisable to be conservative in such scenarios.

But, many authors differ in their opinion with regard to enucleation of large dentigerous cysts. This is largely due to the fact that larger cystic cavities lack organization of a blood clot and formation of new bone is questionable. ${ }^{[12]} \mathrm{A}$ blood clot in a devitalized area is a great risk, as it can easily become infected and may lead to the unwanted consequences of local inflammation. There is also possibility of nerve damage and incomplete removal of cystic lining due to the encompassment of the roots of the posterior teeth by the cyst. ${ }^{[12]}$

However, in a large case series study|15] [Figure 11] a decision tree for treating large unilocular cysts of the jaws has been suggested. The authors recommended enucleation for all the unilocular cysts irrespective of its size followed by chemical cauterization. They also deferred biopsy prior to a definitive surgical procedure as a valid practice. This is because the wound created by biopsy may impede clean first-hand surgical procedure with regards to tissue planes and wound infection. ${ }^{[15,16]}$

We strongly agree with the tenet and further believe that watertight primary closures followed by unstressed jaw movements are crucial for uneventful bone regeneration after enucleation therapy.

In our case, there was an intact lower basal bone, which favored the enucleation therapy. Postoperative maintenance such as sustaining intercondylar distance, avoiding jaw stress by IMF for eight weeks, and using liquid diet subsequently contributed equally for the success of this therapy. However, this type of cases demands a long-term follow-up to monitor for any recurrence.

The above-described approach will certainly prevent the aggressive radical treatment protocol, which would 


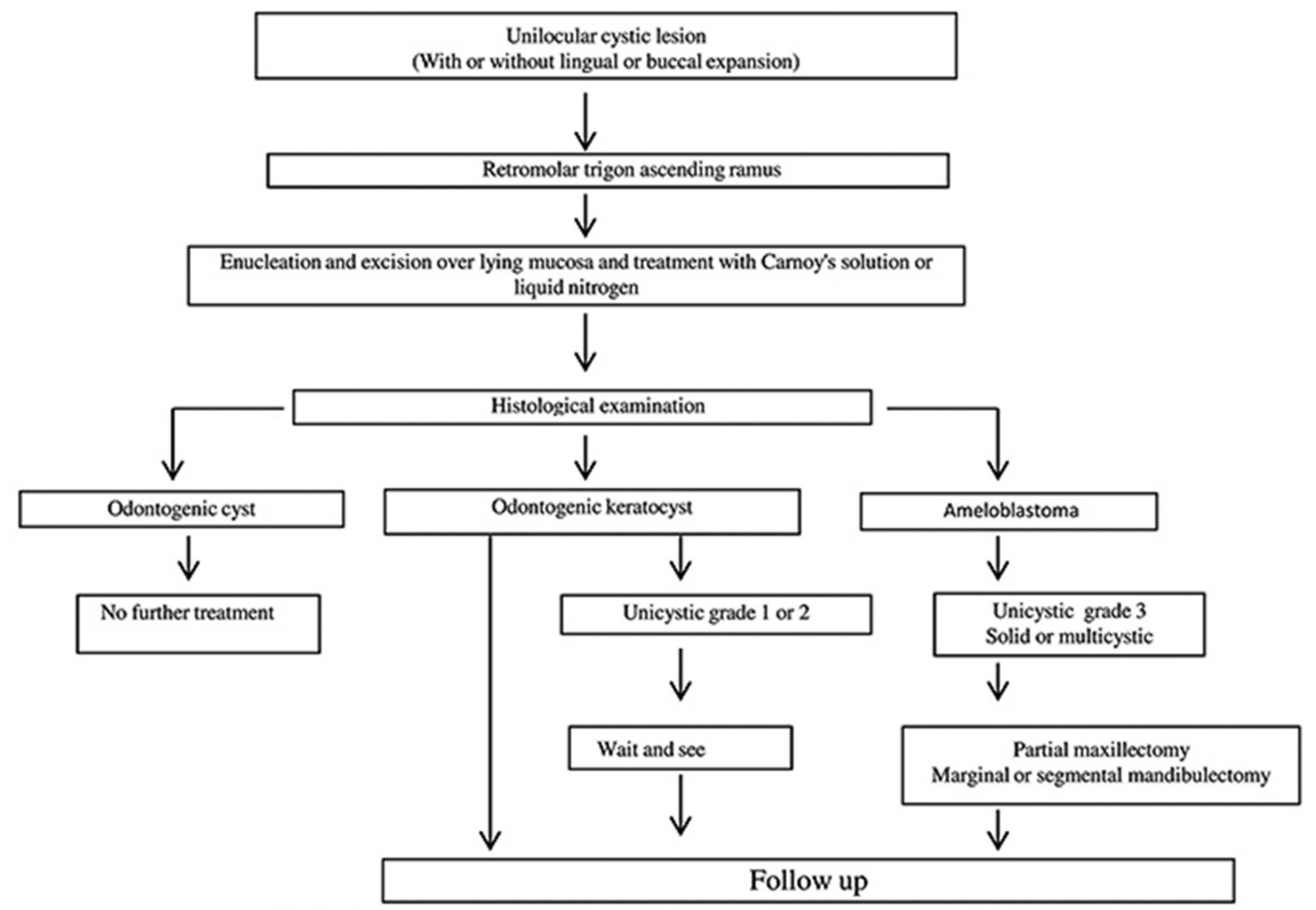

(Adapted from : K.A.O.M. Chapelle et al. Rational approach to diagnosis \& treatment of ameloblastomas \& odontogenic keratocysts. Br J Oral Maxillofac Surg 2004;42: 381-390.)

Figure 11: Decision tree for unilocular cystic lesion in mandibular third molar area that tends to extend in the ascending ramus

be taxing both to the patient as well as surgical team. Therefore, in such cases conservative treatment does have a far better advantage to minimize the postoperative morbidity. In our opinion, this method of treatment would stand us a chance of a radical option if need arises in the course of patient follow-up.

We have observed in our present case, the therapy enucleation alone may holds well in such young aged patients provided the proper preoperative diagnosis and meticulous surgery is carried out. Conversely, the technique chosen largely depends on the surgeon, as even the best technique will not be satisfactory if incorrectly carried out and our case is not an exception.

\section{Financial support and sponsorship}

Nil.

\section{Conflicts of interest}

There are no conflicts of interest.

\section{REFERENCES}

I. Ko KS, Dover DG, Jordan RC. Bilateral dentigerous cysts-report of an unusual case and review of literature. J Can Dent Assoc 1999;65:49-5I.

2. Freitas DQ, Tempest LM, Sicoli E, Lopes-Neto FC. Bilateral dentigerous cysts: review of the literature and report of an unusual case. Dentomaxillofac Radiol 2006;35:464-8

3. Ustuner E, Fitoz S, Atasoy C, Erden I, Akyar S. Bilateral maxillary dentigerous cysts: a case report. Oral Surg Oral Med Oral Pathol Oral Radiol Endod
2003:95:632-5

4. Benn A, Altini M. Dentigerous cysts of inflammatory origin. A clinicopathologic study. Oral Surg Oral Med Oral Pathol Oral Radiol Endod 1996;8I:203-9.

5. Demirkol M, Ege B, Yanik S, Aras MH, Ay S. Clinicopathological study of jaw cysts in southeast region of Turkey. Eur J Dent 2014;8: I07-II.

6. Al Sheddi MA. Odontogenic cysts. A clinicopathological study. Saudi Med J 20I2;33:304-8.

7. Ziccardi VB, Eggleston TI, Schneider RE. Using fenestration technique to treat a large dentigerous cyst. J Am Dent Assoc 1997; 128:20I-5.

8. Marwah N, Bishen KA, Prabha V, Goenka P. A conservative approach in the management of inflammatory dentigerous cyst in transitional dentition: a case report. J Mass Dent Soc 2012;61:18-21.

9. Bozdogan E, Cankaya B, Gencay K, Aktoren O. Conservative management of a large dentigerous cyst in a 6-year-old girl: a case report. J Dent Child (Chic) 201 I;78:163-7.

10. Gulbranson SH, Wolfrey JD, Raines JM, McNally BP. Squamous cell carcinoma arising in a dentigerous cyst in a 16-month-old girl. Otolaryngol Head Neck Surg 2002;127:463-4.

II. Meara JG, Brown MT, Caradonna D, Varvares MA. Massive, destructive, dentigerous cyst: a case report. Otolaryngol Head Neck Surg 1996; I 15:14 I-4.

12. Sokler K, Sandev S, Grgurevic J. Surgical treatment of large mandibular cysts. Acta Stomatol Croat 200 I;35:253-7.

13. Lung KE, Ganatra S, Robinson CE. Multiple multilocular dentigerous cysts with intraosseous and extraosseous third molar displacement: a case report. Oral Health 2006;6:20-9.

14. Isser DK, Das S. Dentigerous cyst in a young boy. Indian J Otolaryngol Head Neck Surg 2002;54:44-5.

15. Chapelle KA, Stoelinga PJ, Wilde PC, Brouns J], Voorsmit RA. Rational approach to diagnosis and treatment of ameloblastomas and odontogenic keratocysts. Br J Oral Maxillofac Surg 2004;42:381-90.

16. Pogrel MA, Montes DM. Is there a role for enucleation in the management of ameloblastoma? Int J Oral Maxillofac Surg 2009;38:807-I2. 